\title{
Hervé Le Tellier, Esthétique de l'Oulipo
}

\section{Laura Brignoli}

\section{(2) OpenEdition}

\section{Journals}

\section{Édition électronique}

URL : http://journals.openedition.org/studifrancesi/9338

DOI : ERREUR PDO dans /localdata/www-bin/Core/Core/Db/Db.class.php L.34 : SQLSTATE[HY000]

[2006] MySQL server has gone away

ISSN : 2421-5856

\section{Éditeur}

Rosenberg \& Sellier

\section{Édition imprimée}

Date de publication : 1 juin 2008

Pagination : 223-224

ISSN : 0039-2944

\section{Référence électronique}

Laura Brignoli, « Hervé Le Tellier, Esthétique de l'Oulipo », Studi Francesi [En ligne], 154 (LII | I) | 2008, mis en ligne le 30 novembre 2015, consulté le 07 janvier 2021. URL : http://journals.openedition.org/ studifrancesi/9338 ; DOI : https://doi.org/ERREUR PDO dans /localdata/www-bin/Core/Core/Db/ Db.class.php L.34 : SQLSTATE[HY000] [2006] MySQL server has gone away

Ce document a été généré automatiquement le 7 janvier 2021.

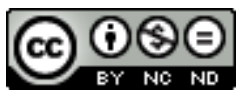

Studi Francesi è distribuita con Licenza Creative Commons Attribuzione - Non commerciale - Non opere derivate 4.0 Internazionale. 


\title{
Hervé Le Tellier, Esthétique de l'Oulipo
}

\author{
Laura Brignoli
}

\section{RÉFÉRENCE}

HERVÉ LE TELLIER, Esthétique de l'Oulipo, Bègles, Le Castor Astral, 2006, pp. 334.

1 La vitalité d'un groupe tel que l'Oulipo se mesure non seulement à l'aune de ses publications collectives, ou des productions individuelles de chacun de ses membres, mais aussi aux ouvrages critiques qu'il engendre, d'autant plus intéressants s'ils ne s'arrêtent pas sur une œuvre ou un auteur spécifique, mais s'ils concernent le groupe dans son ensemble. Huit ans après la Poétique de l'Oulipo (Amsterdam - Atlanta, Rodopi, 1998), dans laquelle Marc Lapprand s'évertuait à parcourir les routes tracées par les oulipiens, un membre du groupe, journaliste, poète, essayiste et romancier, nous présente un autre travail d'importance sur l'Oulipo: la description de son esthétique. L'œuvre se place de façon déclarée sous le signe de la critique de la réception, ce qui fait de cette esthétique une réflexion moins sur la littérarité de l'œuvre oulipienne (qualité d'impossible définition pour n'importe quelle œuvre, en dépit de quelques tentatives largement insuffisantes), que sur l'agrément que le texte sait engendrer auprès du lecteur auquel on reconnaît la capacité de mesurer, grâce au plaisir qu'il éprouve, la 'beauté' d'une œuvre. La complicité entre auteur et lecteur est d'autant plus essentielle pour les oulipiens, que la notion est polysémique si on remonte à son origine étymologique: «complice», observe Le Tellier, dérive du latin complex, tout aussi bien que «complexe». Et la complexité est exactement le chiffre de l'œuvre oulipienne, qui possède «plusieurs centres» (p. 186).

2 Ainsi, après avoir pris en considération le terrain d'où prit naissance le groupe, Le Tellier s'adonne à explorer l'univers de ses inventions linguistiques par lesquelles il faut entendre les véritables créations, comme les langues animales qui puisent dans la tradition burlesque, ou ces mirobolantes inventions dignes de Babel dans lesquelles les 
néologismes se combinent avec la réactualisation des traits les plus lexicalisés de la langue. L'inventaire n'est pas sans évoquer, en sourdine, le caractère non pertinent des réflexions sur la «beauté de la langue» (ch. II); les points de tangence avec formes et ouvrages préexistants, aussi bien que l'intertextualité interne à l'Oulipo; les différentes façons d'impliquer les lecteurs dans l'œuvre, et enfin les horizons de référence qu'elles envisagent: les multiples ressorts de l'écriture ne prétendent nullement pouvoir traduire la complexité d'un monde qui ira toujours bien au-delà de toute œuvre, si ambitieuse soit-elle. 